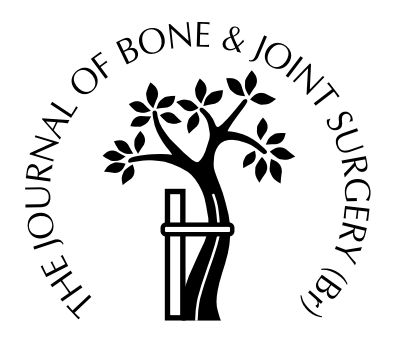

\title{
Resection of the radial head after Mason type-III fractures of the elbow
}

\author{
FOLLOW-UP AT 16 TO 30 YEARS
}

R. P. A. Janssen, J. Vegter

From Elkerliek Hospital, Helmond, The Netherlands

$\mathbf{W}^{\mathrm{c}}$ e reviewed 21 patients with Mason type-III fractures of the radial head treated by resection, evaluating the results at 16 to 30 years by a standard questionnaire and clinical and radiological examination of the elbow and wrist.

Seventeen patients had an excellent result, three were good and one fair. Resection of the radial head is a satisfactory method of treatment of such fractures. Prosthetic replacement seems to be indicated only when there is valgus instability of the elbow.

J Bone Joint Surg [Br] 1998;80-B:231-3.

Received 8 August 1997; Accepted after revision 20 October 1997

It is generally agreed that a comminuted (Mason type-III) fracture of the radial head is best treated by excision when anatomical reconstruction is not possible. ${ }^{1}$ Prosthetic replacement of the radial head in stable elbows is controversial. Many problems have been described at both wrist and elbow after resection of the radial head, but there are few reports of the long-term results after follow-up for over 15 years. ${ }^{2,3}$ We have reviewed our results at between 16 and 30 years after the excision of comminuted fractures of the radial head.

\section{$\underline{\text { Patients and Methods }}$}

We reviewed the case notes of 25 consecutive patients with Mason type-III comminuted fractures of the radial head. Three were excluded because they also had dislocation of the elbow, and three had died subsequent to follow-up examinations at six to 12 years by the second author. One could not be traced. The remaining 18 patients were interviewed and examined at a follow-up of between 16 and 30 years.

R. P. A. Janssen, MD, Orthopaedic Registrar

J. Vegter, MD, Orthopaedic Surgeon

Elkerliek Hospital Helmond/Deurne, Postbus 98, 5700 AB Helmond, The

Netherlands.

Correspondence should be sent to Dr J. Vegter.

(C)1998 British Editorial Society of Bone and Joint Surgery

0301-620X/98/28255\$2.00

VOL. 80-B, No. 2, MARCH 1998
These patients completed a standard questionnaire concerning handedness, the history of other fractures, and operations or conditions involving the arm; pain at the elbow and wrist at rest on movement and at work; fatigue, paraesthesia and grip strength; and work and recreation including any changes due to the elbow condition. Personal satisfaction was recorded as good, fair or poor.

Examination included recording the range of movement of the left and right elbows and wrists, measurement of the valgus angle and the maximum valgus-stress angle of both elbows and of the circumference of the proximal forearms. Grip strength on both sides was tested by averaging three measurements using a Jamar hand meter. We used a functional rating index, modified from An and Morrey ${ }^{4}$ to assess the results of treatment (Table I).

In 16 patients comparative anteroposterior and lateral radiographs of both wrists and both elbows, including maximum valgus-stress views, were taken; two patients refused. The elbow films were evaluated for bony overgrowth of the radial stump, valgus angle and valgus instability, periarticular ossification, proximal radio-ulnar synostosis, osteoporosis and degenerative changes. The wrist radiographs were studied for radial deviation, proximal movement of the radius and degenerative arthritis.

\section{Results}

Details are given in Tables I to III. They show that of 18 patients at a follow-up of 16 to 30 years and three at 6 to 12 years, 20 had good or excellent results by the modified Morrey index. ${ }^{4}$ All were able to continue their work and daily activities without restriction. Only one patient assessed his result as poor, since he had had to stop playing football, snooker and badminton, and change his job from a lift-truck driver to a gardener. He had pain on lifting a bucket of water, had lost $25^{\circ}$ of supination, and his radiographs showed mild degeneration with severe lateral periarticular ossification.

Elbow. Only four patients complained of elbow pain. One had diffuse pain at both elbow and wrist when lifting weights of over $15 \mathrm{~kg}$ with pronation and supination of his (non-dominant) forearm. There was loss of $20^{\circ}$ of supination. Radiographs at the 24-year follow-up showed mild degeneration, some lateral periarticular ossification, and 
Table I. Functional rating index and results

\begin{tabular}{lll}
\hline & Points & $\begin{array}{c}\text { Number of } \\
\text { patients }\end{array}$ \\
\hline Range of movement (0.2 points per degree) & & \\
Flexion (150) & 30 & \\
Extension (10) & 20 & \\
Pronation (80) & 16 & \\
Supination (80) & 16 & \\
Strength & & \\
Normal & 12 & \\
Mild loss (80\% of opposite side) & 8 & \\
Moderate loss (50\% of opposite) & 4 & \\
Severe loss (limits everyday tasks, disabling) & 0 & \\
Stability & & \\
Normal & 12 & \\
Mild loss (no limitation) & 6 & \\
Grossly unstable & 0 & \\
Pain & & \\
None & 12 & \\
Mild (activity normal, no medication) & 8 & \\
Moderate (with or after activity) & 4 & \\
Severe (at rest, constant medication) & 0 & \\
Results & & \\
Excellent & 90 to 100 & 17 \\
Good & 80 to 89 & 3 \\
Fair & 70 to 79 & 1 \\
Poor & $<70$ & 0 \\
\hline
\end{tabular}

Table II. Results of the questionnaire and assessment of range of movement and grip in 21 patients

\begin{tabular}{lll}
\hline & Number & $\begin{array}{c}\text { Loss in } \\
\text { degrees }\end{array}$ \\
\hline Elbow & & \\
$\quad$ Pain & 4 & \\
$\quad$ Limited flexion & 8 & 10 to 40 \\
Limited extension & 1 & 10 \\
Limited pronation & 2 & 20,25 \\
$\quad$ Limited supination & 1 & 10 \\
$\quad$ Limited extension and pronation & & \\
Wrist & 2 & 10 \\
$\quad$ Pain & 2 & \\
Limited dorsiflexion & 1 (after wrist surgery) \\
$\quad$ Limited in all directions & & \\
Grip & 2 & \\
$\quad$ Loss of strength &
\end{tabular}

Table III. Results of the radiological assessment of 16 patients at 16 to 30 years

\begin{tabular}{lcl}
\hline & Number & Amount \\
\hline Increase in cubitus valgus & 7 & 5 to $10^{\circ}$ \\
Valgus instability & 0 & \\
Bony overgrowth of radial stump & 9 & \\
Proximal radio-ulnar synostosis & 0 & \\
Periarticular ossification & 7 & \\
Osteoporosis of the capitellum & 7 & Mild \\
Degenerative arthritis of the elbow & 11 & Mild \\
Radial deviation of the hand & 0 & \\
Proximal radial migration & 12 & 1 to $5 \mathrm{~mm}$ \\
Degenerative arthritis of the wrist & 0 & \\
\hline
\end{tabular}

slight overgrowth of the radial stump. The second patient was experiencing dorsolateral discomfort during strenuous work at the 24-year follow-up, but no functional impairment and only mild radiological degeneration and overgrowth of the radial stump were seen. The third patient has been described above. Radiological evaluation showed mild arthritis and severe lateral periarticular ossification. The fourth had slight pain laterally on strenuous activity at 20 years, but had no functional restriction and no radiological changes.

Twelve patients had some limitation of elbow movement, but only one subjective result was poor. The valgus angle and maximum valgus stress angle were measured using a handheld goniometer with the elbow in maximal extension. Flexion contractures in eight patients limited the accuracy of these measurements.

Wrist. Two patients had wrist pain. One, who also had elbow pain, is described above. The other was a housewife with an aching sensation at the ulnar side of her nondominant wrist after strenuous work at 21 years. Neither patient had restriction of activity or used analgesics. Three patients had loss of movement at the wrist, but two of them had had fractures of the wrists in the past. One patient with a stiff wrist had undergone previous surgery at the wrists. Only two patients had loss of grip strength. One was the former lift-truck driver described above and the other showed some muscular atrophy with $10^{\circ}$ loss of both extension and pronation. The subjective result was good at 19 years with no restriction on work as a truck driver.

Radiological findings (Table III). Twelve patients showed proximal migration of the radius of 1 to $3 \mathrm{~mm}$, but ten of these had no complaints. Two patients with radial displacements of 2 and $3 \mathrm{~mm}$ had $10^{\circ}$ loss of pronation and $20^{\circ}$ loss of supination, respectively, which made it difficult to obtain standard films for the measurement of radial migration. There was periarticular ossification in seven patients, on the lateral side in five and the medial in two. Five of these patients had reduced elbow movement, as did five of the nine patients with overgrowth of the radial stump. Both overgrowth and periarticular ossification were seen in five patients; three had limitation of movement, but this was also found to a less extent in three of the five patients without overgrowth or periarticular ossification. Mild degenerative arthritis of the elbow with minimal osteophytes or joint narrowing or both ${ }^{5}$ was seen in 11 patients.

\section{Discussion}

Early resection and mobilisation are recommended for Mason type-III fractures of the radial head to avoid later functional impairment, ${ }^{1,3}$ but some patients may have loss of extension. ${ }^{3,6,7}$ Our long-term review showed a distinct discrepancy between loss of movement and subjective satisfaction, since only one patient was restricted in his activities. In the past, limited elbow movement after resection of the radial head has been attributed to damage to the cartilage of the humerus and the trochlear notch, overgrowth of the radial stump, ${ }^{9}$ or to bony osteophytes and periarticular ossification. ${ }^{6}$ Our series is too small for statistical analysis, but there seemed to be some correlation between radial overgrowth or periarticular ossification and loss of mobil- 
ity. All the patients with limited rotation of the forearm had definite heterotopic ossification. We have recently started to use a course of indomethacin after resection of the radial head to try to reduce such ossification.

Replacement of the radial head by prostheses remains controversial. ${ }^{10}$ Silicone implants have shown problems due to the material itself, and the lack of stiffness to withstand normal loads without deformation. ${ }^{11,12}$ Metal prostheses have given satisfactory results for unstable fractures of the radial head, ${ }^{13-15}$ and vitallium heads used to treat fracture dislocations are reported to have given minimal problems with dislocation or implant failure. ${ }^{16}$

Biomechanical studies have shown that the medial collateral ligament of the elbow is important in providing valgus stability after resection of the radial head. The stabilising effect of the head comes into play only after this ligament has been disrupted. ${ }^{5,17}$ We found no valgus instability after resection of the radial head, and attributed this to intact medial collateral ligaments. We therefore support the opinion of Morrey et al that valgus stability is provided by an intact medial collateral ligament, and that no prosthetic implant is necessary after resection of the radial head when this ligament is intact. 5,17

Proximal displacement of the radius with subluxation of the distal radio-ulnar joint after resection of the radial head has been described by many authors, $1,3,5-7,9,11,18-24$ but there is disagreement as to the symptoms which may result. Some have reported no subluxation at the distal radio-ulnar joint, ${ }^{8,25}$ but Radin and Riseborough ${ }^{23}$ described three patients with proximal radial migration after fractures of the radial head which had not been excised. Some authors describe no correlation between wrist complaints and subluxation of the distal radio-ulnar joint,,$^{3,5,7,18,23}$ but others have shown a relationship between the two. ${ }^{6,9,11,19-22,24} \mathrm{We}$ found proximal radial migration in accordance with previous research, but no definite correlation between this migration and wrist complaints, functional impairment, or degenerative changes at the wrist or elbow.

Morrey et $\mathrm{al}^{5}$ describe a correlation between pain and degenerative arthritis of the elbow or wrist after resection of the radial head, but none between arthritic changes and functional impairment or loss of strength. We found no evidence of degenerative changes at the wrist in our series, and only mild arthritis of the elbow which was unrelated to limited movement or pain. No patient had ulnar nerve symptoms such as are described in cubitus valgus. ${ }^{6}$ Osteoporosis of the capitellum was noted in seven patients, but in our opinion, has no clinical significance.

Our long-term follow-up shows that early resection of the radial head is a good treatment for Mason type-III comminuted fractures. Prosthetic replacement seems to be indicated only when there is definite valgus instability after severe trauma.
No benefits in any form have been received or will be received from a commercial party related directly or indirectly to the subject of this article.

\section{References}

1. Morrey BF. Current concepts in the treatment of fractures of the radial head, the olecranon, and the coronoid. J Bone Joint Surg [Am] 1995; 77-A:316-27.

2. Goldberg I, Peylan J, Yosipovitch Z. Late results of excision of the radial head for an isolated closed fracture. J Bone Joint Surg [Am] 1986;68-A:675-9.

3. Postacchini F, Morace GB. Radial head fracture treated by resection: long-term results. Ital J Orthop Traumatol 1992;18:323-30.

4. An KN, Morrey BF. Biomechanics of the elbow. In: Morrey BF, ed. The elbow and its disorders. Philadelphia: WB Saunders, 1985: 43-61.

5. Morrey BF, Chao EY, Hui FC. Biomechanical study of the elbow following excision of the radial head. J Bone Joint Surg [Am] 1979; 61-A:63-8.

6. Mikic ZD, Vukadinovic SM. Late results in fractures of the radial head treated by excision. Clin Orthop 1983;181:220-8.

7. Rokjaer M, Knudsen H. Fractures of the head and neck of the radius treated by excision. Acta Chir Scand 1972;138:793-7.

8. Mason ML. Some observations on fractures of the head of the radius with a review of one hundred cases. Br J Surg 1954;42:123-32.

9. King BB. Resection of the radial head and neck: an end-result study of thirteen cases. J Bone Joint Surg 1939;21:839-57.

10. Bennett JB. Radial head fractures: diagnosis and management. J Should Elb Surg 1993;2:264-73.

11. Wallace AL, Walsh WR, van Rooijen M, Hughes JS, Sonnabend DH. The interosseus membrane in radio-ulnar dissociation. $J$ Bone Joint Surg [Br] 1997;79-B:422-7.

12. Stoffelen DV, Holdsworth BJ. Excision or silastic replacement for comminuted radial head fractures: a long-term follow-up. Acta Orthop Belg 1994;60:402-7.

13. Carr CR, Howard JW. Metallic cap replacement of radial head following fracture. Western J Surg (Obstet and Gynec) 1951;59: 539-46.

14. Edwards GE, Rostrup O. Radial head prosthesis in the management of radial head fractures. Can J Surg 1960;3:153-5.

15. Harrington IJ, Tountas AA. Replacement of the radial head in the treatment of unstable elbow fractures. Injury 1981;12:405-12.

16. Knight DJ, Rymaszewski LA, Amis AA, Miller JH. Primary replacement of the fractured radial head with a metal prosthesis. J Bone Joint Surg [Br] 1993;75-B:572-6.

17. Morrey BF, An K-N. Functional anatomy of the ligaments of the elbow. Clin Orthop 1985;201:84-90.

18. Carstam N. Operative treatment of fractures of the head and neck of the radius. Acta Orthop Scand 1950;19:502-26.

19. Af Ekenstam F, Hagert CG. Anatomical studies on the geometry and stability of the distal radio-ulnar joint. Scand J Plast Reconstr Surg 1985;19:17-25.

20. Geel WC, Palmer AK. Radial head fractures and their effect on the distal radioulnar joint: a rationale for treatment. Clin Orthop 1992; 275:79-84.

21. Lewis RW, Thibodeau AA. Deformity of the wrist following resection of the radial head. Surg Gynecol Obstet 1937;64:1079-85.

22. McDougall A, White J. Subluxation of the inferior radio-ulnar joint complicating fracture of the radial head. J Bone Joint Surg [Br] 1957; 39-B:278-87.

23. Radin EL, Riseborough EJ. Fractures of the radial head: a review of 88 cases and analysis of the indications for excision of the radial head and nonoperative treatment. J Bone Joint Surg [Am] 1966;48-A: 1055-64.

24. Taylor TKF, O'Connor BT. The effect upon the inferior radio-ulnar joint of excision of the head of the radius in adults. J Bone Joint Surg [Br] 1964;46-B:83-8.

25. Murray RC. Fractures of the head and neck of the radius. Brit J Surg 1940;109:106. 